\title{
Intelligent Tutoring Supported Collaborative Learning (ITSCL): A Hybrid Framework
}

\author{
Ijaz Ul Haq ${ }^{1}$, Aamir Anwar ${ }^{2}$, Iqra Basharat ${ }^{3}$, Kashif Sultan $^{4, *}$ \\ Department of Software Engineering, Bahria University Islamabad Campus, Pakistan ${ }^{1,3,4}$ \\ Department of Computer Science, Shaheed Zulfikar Ali Bhutto Institute of Science \& Technology \\ Islamabad Campus, Pakistan ${ }^{2}$
}

\begin{abstract}
Recently Intelligent Tutoring Systems (ITS) and Computer-Supported Collaborative Learning (CSCL) have got much attention in the field of computer science, artificial intelligence, cognitive psychology, and educational technologies. An ITS is a technologically intelligent system that provides an adaptive learning paradigm for an individual learner only, while CSCL is also a technology-driven learning paradigm that supports groups of learners in pertaining knowledge by collaboration. In a multidisciplinary research field-the Learning Sciences, both individual and collaborative learning have their own significance. This research aims to extend ITS for collaborative constructivist view of learning using CSCL. Integrating both design architecture of CSCL and ITS, this research model propose a new conceptual framework underpinning "Intelligent Tutoring Supported Collaborative Learning (ITSCL)". ITSCL extend ITS by supporting multiple learners interacting system. ITSCL support three different types of interaction levels. The first level of interaction supports individual learning by learner-tutor interaction. The second and third level of interaction support collaborative learning, by learner-learner interaction and tutor-group of collaborative learners' interactions, respectively. To evaluate ITSCL, a prototype model was implemented to conduct few experiments. The statistical results extrapolate the learning gains, measured from Paired T-Test and frequency analysis, contend a significant learning gain and improvement in the learning process with enhanced learning performance.
\end{abstract}

Keywords-Intelligent Tutoring System (ITS); ComputerSupported Collaborative Learning (CSCL); Artificial Intelligence (AI); individual learning; collaborative learning

\section{INTRODUCTION}

Intelligent Tutoring System (ITS) uses Artificial Intelligence (AI) techniques to provide intelligent tutors in some domains without human intervention. The intelligent tutoring system discovers the diverse status of student experiences and gives adaptive feedback to enhance the learning process [1]. The research community in Artificial Intelligence Education (AIED) has been mostly focusing on the development of one-on-one ITS. While the field of learning sciences is now focused on the integration of individual and collaborative learning. In collaborative learning, peer learners collaborate to solve a problem, encourages peers to explore ideas, present and defend arguments, exchange of ideas, conceptual mapping, reflect and elaborate upon their knowledge. Traditional non-collaborative ITS, geared towards a single learner, despite the different positive impacts of individual and collaborative learning. The

\footnotetext{
*Corresponding Author
}

one-on-one intelligent tutoring system is not in accordance with a collaborative constructivist view of learning. In single learner (learner-tutor) ITS, there are boundaries among the learners with no real-time interaction or knowledge sharing on problem-solving. The adaptive and flexible intelligent tutoring model allows us to extend this to collaborative intelligent tutoring. To extend the scope and application of ITS for collaborative learning, Computer-Supported collaborative learning (CSCL) holds the potential in a broader range for collaborative learning.

Computer-Supported Collaborative Learning (CSCL) uses computer technology for promoting students' collaboration [2]. CSCL aims to support groups of students in getting knowledge by collaborating in a specific domain using a computer as mediation [3]. Collaboration in a coordinated system is a more challenging task [4]. An important study concluded that developing an intelligent system for CSCL is more challenging to improve collaborative learning and development of collaboration skills [5].

ITS and CSCL both are the multidisciplinary areas of cognitive psychiatry, computer science, and educational technologies, etc. CSCL and ITS provide pedagogically, cognitive and scaffolding of learning. In computer-based learning environments, ITS is assisting students in acquiring knowledge [6]. ITS and CSCL are computer-mediated platforms that monitor interaction patterns and provide feedback to learners. Communication in CSCL is interactive, dynamic, varied and unpredictable while ITS intelligently communicates with the learner. The important feature in CSCL learning is the collaborative peer learner having a shared understanding within the learning environment, on the other side in ITS environment learning is only from an intelligent system that supports in improving personal learning skills. CSCL researchers are focusing on exploring issues of adaptivity, interaction analysis, and feedback. These research aspects of CSCL are getting closer to the techniques of ITS research. Leveraging CSCL approaches could be promising towards combining individual and collaborative learning within ITS. CSCL in ITS integration means, multiple learners interact with the system and with each other for collaborative learning. This endeavor holds the potential for extending the scope and application of ITS in a broader range.

This research shifts the paradigm from traditional ITS that is limited to the single learner to ITSCL, as ITSCL encapsulates both individual and collaborative learning. To conceptualize ITSCL, the architecture of ITS with individual 
learning capability and collaborative learning concepts from CSCL is considered. In ITSCL, individual and collaborative learning could be achieved through different learners' interactions. ITSCL provides three different types of interactions. The first level of interaction is learner tutor interaction which is the focus of ITS development. ITSCL second level interaction will be between peer learners. This depicts that learners may reap benefits from the peer learners. The third level of interaction will enable ITSCL interaction between a tutor and a small group of collaborative learners. ITSCL is promising towards combining individual and collaborative learning of a small group of learners within ITS environment.

Following introduction, this paper is organized as: Section II deliberates the review of literature. The architectures of ITS and CSCL is presented in Section III and IV. Based on these architectures ITSCL framework is proposed in Section V. The prototype implementation of the proposed model is presented in Section VI. Evaluation and findings are mentioned in Section VII, following by experimental results and discussion in Section VIII. Lastly, conclusion and future is drawn in Section IX.

\section{LITERATURE WORK}

From prior research, it is inferred that CSCL environments lacks cognitive and adoptive support [7]. An ITS is a prime AI application that provides cognitive and adoptive support, that can be beneficial for collaboration to be successful. Very few studies incorporate the optimal mode of combining individual and collaborative learning in integrated CSCL and ITS environments, mostly collaboration achieved by group formation outside ITS environment through asynchronous communication. Effective collaboration script does not follow simply by group formation. Several exemplary works using CSCL with ITS are described here to provide our research background.

Pierre Tchounikine et al. explored interaction analysis i.e. individual's and collaborative group's interactions are used. In the CSCL environment to provide students with adoptive support, ITS has been used. They outlined the requirements for technological platforms, supporting learners with adaptive guidance and feedback [8]. Maria Virvou proposed a system that incorporates an adaptive system, learner module, error diagnosis, advice generative module, and collaborative module. Collaboration is carried out by asynchronous text messaging in two different languages (French and English) [9]. Another investigation by Maria Virvou et al, the study considered user modelling and machine learning. User modelling is used to collect and analyze user characteristics, also considering these characterizes incorporated to create student groups by using machine learning. These resulting groups promote win-win collaboration [10]. This study only focuses on collaborative learning but they did not explore in ITS environment. Another important study was done out by Daniel Epstein et al, a text-mining tool elaborates on the interaction of the learners within ITS environment. Students are requested to make questions. The learners are required to post questions, using a machine learning approach system to extract meaningful and relevant terms from their text and the triggering text to extract keywords. These keywords are sent to a web search that retrieves its information [11]. This study does not encourage learner's collaboration instead they seek help from the web. Ronald Cole et al, studied learners' interactions with Marni (virtual science subject tutor). This research investigated that the impact of interactions on learners demonstrated similar significance gains in learning achievement [12]. The collaboration of the students was recorded without involving a tutor; the students discuss and provide a group answer to the tutor. Pravin Chopade et al. enable the ITSs that facilitate collaborative problem solving (CPS). Team interaction data was collected from log data, eye-tracking, and video/audio [13]. The students discuss and collaborate though audio/video platform. Since students achieved collaboration outside ITS system A Generalized Intelligent Framework for Tutoring (GIFT) also supports effective adaptive feedback to an individual learner or team of learners [14]. GIFT assist teams of soldiers, but its implication is only for soldier's teamwork. Another study applied common concepts in the human-agent team, such as task allocation, adaptive triggers, and behavior modelling [15]. Most of the studies achieve collaborative learning outside the ITS environment. Some worked on learning group formation, sharing problem view, learner response sharing, and learner communication audibly and through text messaging or chat communication, etc.

Jennifer K. Olsen et al, Continuously worked for many years to integrate CSCL and ITS and to achieve collaborative learning. ITS authoring tool is extended to Cognitive Tutor Authoring Tools (CTAT), to support collaboration scripts using example-tracing collaborative tutors. This collaboration was obtained by applying multiple parallel example-tracing tutor engines, one engine for each student. These engines collect all the inputs from every student and send outputs to all students [16]. These engines collaborate to share information on peer learners. Another study tests the hypothesis that collaboration may be more beneficial for conceptual knowledge, and less optimal for procedural skills. The dual eye-tracking technique was used to evaluate this hypothesis about collaborative learning [17]. The collaborative version of Cognitive Tutor Authoring Tools (CTAT), where students have shared problem view that can be differentiated through adoptive guidance/feedback, and problem information [18] Jennifer et al, explore; collaboration support for elementary level students using ITS system, raising the strength of collaborative and individual learning in conceptual and procedural knowledge and benefits of two learning methods better than either one alone [19]. The research focused on the analysis of students' interactive dialogue and their behavior in an Intelligent Tutoring System (ITS). The research found that the frequency of interactive talk and errors overtime decrease in the group of two learners working together on conceptual problems [20]. The study investigated the benefits of combining individual and collaborative learning. The results showed that the combined condition had higher learning gains than either alone in individual or collaborative [21]. In cognitive group awareness, every learner answers the question individually, the peers shared their answers, and then they are acquired to provide a collaborative answer [22]. Jennifer K. Olsen et al further investigated how the system constructs 
knowledge collaborative using log data, student interactive dialogue, and eye-gaze analysis [23]. All these studies explore collaborative learning in ITS with different angles. The author successfully extends ITS for collaborative learning as well. Although this research work nicely contributes to integrating ITS and CSCL, this research has opened an inquiry into how collaborative and individual learning can be effectively combined. Also, there are some limitations to their work. First, CTAT is only of mathematical fraction problem. The authors did not give any explanation that this domain allows a certain degree of discussion among the students. Selecting the nominator or denominator by each learner or selecting an answer from radio buttons does not allow a certain degree of communication and collaboration. Second, this collaboration is limited to only two learners. As in CTAT equivalent fraction is a two-student activity. An increase in several learners could complex the interaction analysis; most importantly that collaborative learning is not only between learners. The optimal collaborative learners' group size is four. Third, this study more focuses to investigate the outcome of collaborative learning in procedural and conceptual problems rather than general. Fourth, with no prior group formation of the learners, teachers randomly assign learners to a group based on their abilities. Fifth, the learner communicates with another learner through Skype which is recorded but this is outside ITS environment. CTAT itself not capture learnerlearner interactions. Sixth, Poor communication among students, as students communicate outside ITS environment, so ITS could not analyze their interaction, engagements, reasoning and sharing knowledge and ideas.

Another important contribution to the collaborative learning in ITS is carried out by Richel Harslely, at the University of Illinois at Chicago. This is also the most relevant study that integrates CSCL and ITS. Harsley extends ChiQat tutor for collaborative learning as well. ChiQat works for programming problems. ChiQat is extended to Collab-ChiQat to support collaborative learning between two pair programmers. Collab-ChiQat provides two types of collaboration. First Non-structured collaboration, that does not provide any feedback on collaborative pair. Second is structured collaboration, that visual feedback on the group and individual performance. Both students logged to the system in a collaborative mode. One student involves in coding and the system monitors the performance while the other helps the peer coder and then turn change accordingly. The students used the headset to record their Skype dialogue [24] [25] [26] [27]. Richel Harsley successfully extends ChiQat to CollabChiQat. Collaborative-ChiQat achieves the meaningful collaboration of two learners for a pair programming task. But there is some limitation of these research findings. First, Collab-ChiQat provides collaboration between two learners, but collaboration may involve more than two users. Second, Collab-Chiqat is for pair programming domains that involve only two learners in collaboration. It does not provide a higher degree of collaborative learning. The pair programming domain does not allow a certain degree of discussion among the students. Collaborative groups of more learners could achieve higher learning gains rather than two learner's collaboration. Third, Learners are stationed on a single stationed computer, and their collaboration is not recorded inside ITS. Fourth, these studies mostly focus on unstructured and structured collaboration rather than a high collaboration script. Fifth, the ITS only measures the performance of the coder, with no collaboration script inside ITS system. Sixth, Students wear headsets to record spoken dialogue. This collaboration could be analyzed by ITS. The students seek help from a peer by spoken dialogue that is outside ITS domain.

The novelty from recent work with real-time support of peer learner's collaboration is facilitated by ITSCL. ITSCL drove the design of ITS for collaborative learning. This enhancement to the framework of traditional one-on-one ITS will provide a collaboration platform where the learner can seek help from peer learners. In the above literature work, ITS is extended for the only group of two students. Also, ITS domain selected was pair programming and fraction problems, which does not involve logical reasoning between two students. ITSCL support a small group of students and provide a different level of interaction among learners. ITSCL provides individual learning by Learner-ITS interaction. It also supports collaborative learning by learner-learner interaction and a tutor-small group of learners. This means of collaboration by ITSCL will increase its learning effectiveness. CSCL community necessitates exploring how students acquire knowledge with real-time support of peer learner's collaboration inside an ITS. The ability to integrate these two ideas (CSCL and ITS) to effectively ameliorate learning remnant is a challenge. This endeavor holds the potential for extending the scope and application of ITS in a broader range for collaborative learning.

\section{ITS ARCHITECTURE}

Historically research has been focusing on one-on-one ITS, its different tutoring techniques, different scaffolding techniques, student and domain modules. The architecture of traditional one-on-one ITS consists of four modules namely, tutor module, domain module, learner module, and user interface [28] shown in Fig. 1.

\section{A. Tutor Module}

It contains all the tutoring strategies for the student. It accepts information from the domain module and the student module. Making use of student module it decides the tutoring strategies, techniques and tactics as well.

\section{B. Domain Module}

This module contains the domain knowledge of a specific subject. It includes information about a specific domain/topic. Domain model serves as an expert knowledge which tackles different issues, diagnosis of error provides a standard for learner performance evaluation or to response questions postured by students.

\section{Student Module}

The student module stores all the information about the student. The student model is used to interpret leaner behavior using ITS. So, the student model emphasizes on cognitive (learner knowledge) and effective (behavioral) states. 


\section{Interface Module}

Learners interact with ITS through the interface. The learner acquires knowledge from ITS interacting by the user interface. The learner acquires learning material from ITS and gives reactions to the learning material. Learning material may include text, graphics, audio, and multimedia, etc. Traditional one-on-one ITS provides a single learner interface as shown in Fig. 1 .

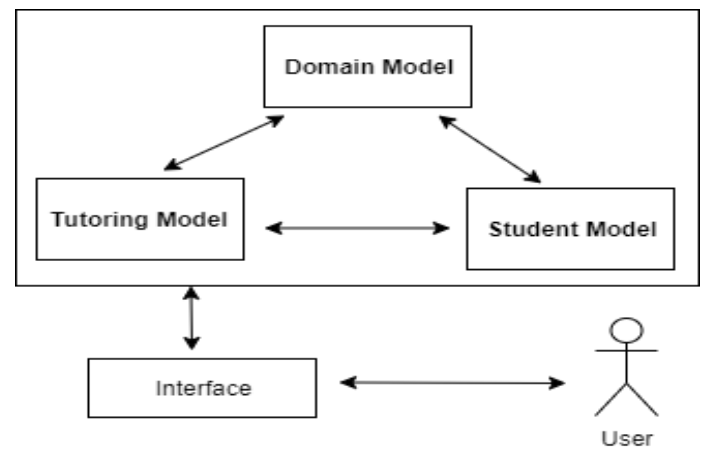

Fig. 1. ITS Architecture [28].

\section{CSCL ARCHITECTURE}

CSCL script has different architectures. The most relevant architecture of CSCL that relates to our study is the distributed architecture of CSCL.

A distributed architecture is characterized by the distribution of the Model View Controller (MVC) architecture. MVC is the sharing of components across multiple hosts. In MVC architecture model lives on a shared server and each user has its view and controller as shown in Fig. 2. Each user sits on his computer having his interface view and control. The distributed architecture of CSCL shares features on a live shared and centralized server where specification of view and controller are maintained on the server and sent to user. This supports multiple users connecting across a shared server. Daniel D. Suthers present distributed architecture for CSCL [29].

As distributed architecture supports multiple users in the CSCL environment, so using this architecture collaboration can be fostered in ITS as well. To achieve collaboration in ITS, the distributed architecture of CSCL will support multiple learners to collaborate in the learning process having their own view and control of the system. Multiple learners could interact with ITS and ITS could respond to many learners. This study uses the distributed architecture of CSCL with ITS to achieve both individual and collaborative learning in the ITS environment. Collaboration is one of the emerging learning paradigms in intelligent tutoring systems and education.

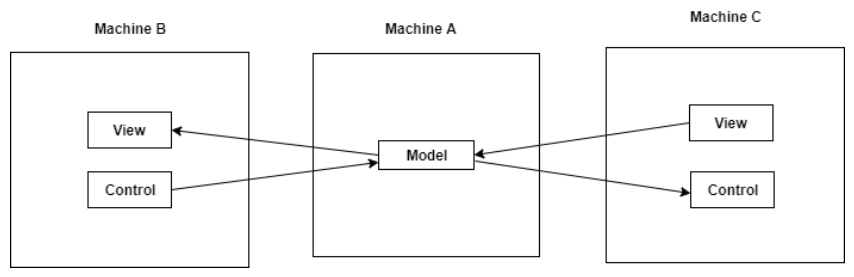

Fig. 2. CSCL Distribute Architecture [29].

\section{PROPOSED FRAMEWORK}

This proposed framework of an intelligent tutoring supporting collaborative learning (ITSCL) supports both individual and collaborative learning. This system supports three types of interactions. First, Learner-Tutor interaction, second is learner-learner and third is a group of learners-ITS interaction.

\section{A. Individual Learning}

State of the art ITS provide an intelligent individual learning facility. This traditional ITS is also referred to as oneon-one ITS (learner-ITS). In one-on-one, ITS single learner interacts with ITS and ITS provides an intelligent support for learning. ITSCL facilitates individual learning by learner-ITS interaction (as shown in Fig. 3 single learner interact using individual learning interface). ITS ask questions from the learner and learner respond to ITS questions. ITS provides adaptive, intelligent feedback and multi scaffolding teaching without human teacher support.

\section{B. Collaborative Learning}

One-on-one non-collaborative learning is extended to collaborative learning in the proposed ITSCL framework. Thus, ITSCL supports the collaborative view of learning as well. This collaborative learning is supported by learnerlearner interaction and a small group of learners-ITS interaction.

1) Group of learners-ITS interaction: Collaborative learning is accomplished by ITSCL through the group of learners-ITS interaction. All the learners have the same problem view of the ITS. Every learner sits on their computer having a control view that also has a shared problem view with peer learners. System asks the question from a group of learners. This question or problem is shared with all groups of collaborative learners on their interface. Every learner has its control to respond to the system question. So, each learner provides an individual answer at the first step. The answer provided by each learner is shared among all the peer learners. Answer sharing helps learners to get a concept or idea of different responses of the peer learners. After sharing of answers, the learner can collaborate with peer learners by commenting on the peer learners. If the peer learner misses any point or concept in the answer, the peer learner can help and guide on commenting on the shared answers. Every learner is capable of sharing knowledge with a peer by commenting on peer answers. This activity will help learners to share knowledge, ask a question, clear their concept, conceptual understanding transformation, articulate their misconception, collaborate and reflect and apply their knowledge. This also helps students to be more interactive and collaborative. Its helps to increase their interest in response to peer's answer and to express how much he agrees or satisfy with peer answer. After getting a response from peer comments and rating answers, the learner can edit their answers according to peer help to respond to his answer. The system allows the student to modify up to two iterations. If the students edit their answers, the system will show the edited 
iteration. Then students finalize their answers. After finalizing, the system will use the Natural Language Process (NLP) to compare or match the finalized answers with the answers in the database. The system chooses that answer as a collaborative answer that highly and best match the system answer. The system accepts the most identical answer as a collaborative answer and provides an adoptive response to all the learners. So, using this activity the learners can best collaborate with the peer learners.

This activity is very useful in many ways. Foremost, every leaner has a shared problem view and control. This breaks the boundaries among learners and makes learners able to work on a single problem together. It also supports every learner to interact with the system and respond. Moreover, this system captures the individual response of each learner. This helps that every learner must have to participate in the activity. Also, we can measure his learning gains from peer collaboration that how much he modifies his answer. Thirdly, the system is highly helpful in knowledge sharing among collaborative learners. Every learner could respond to the peer's answers by commenting on answers. This system ensures highly appreciation and facilitation learners to share knowledge, argue, guide, modify concept, enhance learning and reflect upon their knowledge utilizing commenting on peer answers. Likewise, Students could reflect upon their knowledge by getting responses, guidance, and knowledge sharing in comments. Learners could modify their answers from getting feedback or knowledge from peers. These answer modifications help the learners to enhance their knowledge level and to be more productive.

2) Learners-learner interaction: Learner-learner interaction frequently used technique connecting a group of learners via computer networks. Tighter integration of the learners through chat provides a richer collaborative learning environment [30]. ITSCL provide the third level of interaction by mean of learner-learner interaction. The learner could interact and could seek help from peer learners in a private chat tool. This chat between learner and learner is more focused and productive.

The integrated model of ITS and CSCL into ITSCL, that support individual and collaborative learning by mean of three levels of interaction (learner-ITS interaction, Group of Learner-ITS interaction and learner-learner interaction) is shown in Fig. 3.

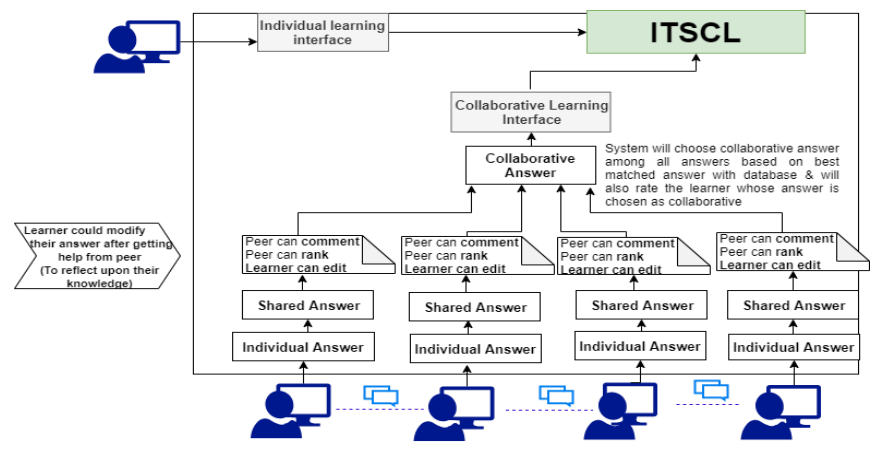

Fig. 3. Proposed ITSCL Framework.

\section{IMPLEMENTATION}

The proposed framework of ITSCL is practically implemented into a prototype. This prototype of ITS extends traditional ITS for collaborative learning as well. While many ITS have been used for one-on-one learning, but we used NDLtutor (Negotiation-driven learning tutor). NDLtutor was introduced as an ITS that uses negotiations as a platform for providing instructions to the learners [31]. ITSCL prototype contains all the basic functionalities of NDLtutor along with the deployment of collaborative learning techniques. ITSCL prototype was developed HTML5 (Hypertext Markup Language) and PHP (Hypertext Pre-processor) along with MySQL database. ITSCL performs two main functionalities, a) One-on-one ITS, b) Collaborative ITS.

\section{A. Individual Learning}

This is the same functionality that is already provided by existing one-to-one ITS. Inside this environment, the learner works individually without any communication or collaboration with other learners as shown in Fig. 4. ITSCL provides a natural language interactive interface. ITSCL provides tutoring to single learning by the Negotiation Driven Learning (NDL) paradigm of NDLTutor [31]. NDL provides learners to interact with the ITS in an intuitive natural language paradigm. ITSCL asks a question from the learner that guides and facilitate to construct their knowledge. The learner provides the response and Tutor interprets learner response and provides adaptive feedback.

\section{B. ITSCL Collaborative Environment}

Collaborative learning involves a group of learners in a learning activity by communicating and collaborating. ITSCL provides collaborative support for learners to work on the same problems. A small group of leaners collaborate with peer learners in the learning process and headed towards the solution of the problem. Learners interact with the tutor from their personal computer having the same problem view. ITSCL first asks the students to record individual responses to the question posed. ITSCL provides an opportunity for every learner to respond a step individually to the ITS question before working on the step as a group. This step is very helpful to actively involve every learner in the collaborative process.

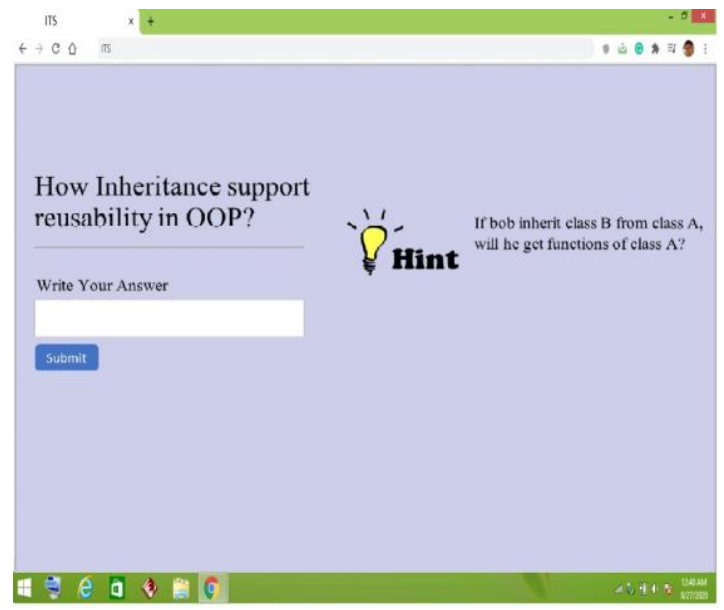

Fig. 4. Individual Learning Interface. 
The learner responses are then shared with the peer learners. Every learner can see the peer answers. Sharing of knowledge with collaborative learners is an essential approach in the collaborative learning process. This helps the learner to access peer knowledge in a specific domain. If learners with their different knowledge levels working on the same problem domain, then knowledge flow from high performing students to weak students. This also helps to construct knowledge from peer knowledge if learner missed in individual response.

After individual answering and sharing of answers with colleagues, ITSCL allows the student to access peers' answers and give them rating as stars to the answers and the updated answers. Rating peer response in a small collaborative group of learners could be a method to foster collaboration and provide an encouraging result [32]. This rating procedure allows learners to read and rate the contribution of their peer collaborative members, which can led to a common understanding and constructing knowledge. This helps the learners to look into the peer's responses and how much they agree to the proposed solution. The responses having a high rating might be the most relevant or correct answer. This rating expresses the cognitive contribution of the participants.

As the responses of the learners are shared and can be viewed to other learners. Every learner is also able to guide and help the peer learner by commenting on peer answers. The learner could point out the missing concepts, provide useful guidance and positive feedback on peer answers. This is a valuable activity that helps the learners to reflect upon their knowledge. This allows learners to construct reasoning on their knowledge level, address their knowledge gap and tend towards the problem solution. When learners actively involve themselves, by sharing knowledge and performing collaborative activities with peer learners, it could influence each other's thought processes, articulate reasoning, memory retrieval, rational behavior, and advance their knowledge. In this process, information or knowledge flows from high performing to low performing students among the collaborative group. After getting clues, help, guidance, concept, and knowledge from peer participants, learners can reflect upon their knowledge and can review their answers twice for the same problem. After finalizing the answers, ITSCL analyzes each learner's responses. ITSCL select authentic answer as collaborative and also identify student whose answer is chosen as collaborative. The system also measures every individual response and shows its result to the student while the collaborative chosen answer is shared with all of the members from the collaborative group. This helps learner's individual as well as collaborative accountability in a collaborative group. ITSCL collaborative mode of learning is presented in Fig. 5.

\section{VII.Evaluation AND FINDINGS}

\section{A. Method}

For ITCSL evaluation an experiment was performed to test system performance and efficiency and later on comparison was made with one-to-one ITS. The experiment consisted of two different ways of evaluation.

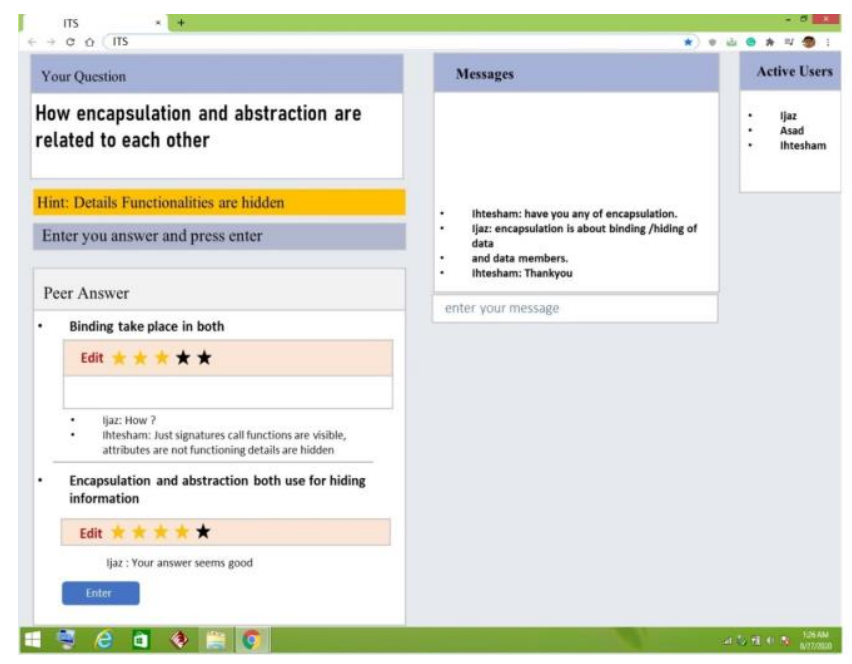

Fig. 5. Collaborative Learning Interface.

Firstly, students learning gain was measured in individual and collaborative conditions. These learning gains were calculated from Pre-Test scores and Post-Test scores of the individual learner. The evaluation further shows the efficiency and performance of the ITSCL concerning the learning gain of concerned learners. Learning gains were analyzed using statistical methods of Paired T-Tests. Students learning gains were analyzed in both individual and collaborative conditions. Secondly, a post-experiment survey was conducted to record user response regarding the usability, effectiveness, and application of both systems and the final verdict of preferring rather a single tutoring system or ITCSL.

\section{B. Participants}

For experimentation purpose, we have selected 28 undergraduate students from Bahria University Islamabad Pakistan. This study took place in one session in a computer science programming lab. Those participants were students from the under-graduate program and were selected because they were taught programming concepts for four semesters. They had the experience of using online learning environments, but none of the participants had previous experience or any idea about intelligent tutoring systems. The experiment was conducted on ITSCL that uses NDLTutor technique [31]. Before the session, participants were oriented on how to use the ITSCL and the different available options about the usage.

\section{Student's Group Selection}

In CSCL generally, small groups of learners are organized using random, self-selection, quiz/assignment or grading-wise selection. In this experimental procedure, the teacher divided students into different groups. The size of the group also matters in CSCL. Smaller groups (less than three) contain less diversity and lack social constructivism, whereas participants in the larger group are difficult to ensure full participation and can lead to complex communication structures. Furthermore, we used the group size of four students. As the students were participating, thus the availability of seven groups of four students was confirmed. 


\section{Procedures}

The experiment was conducted during the students' regular class timings. It was a single interactive session divided into the following stepwise procedure also shown in Fig. 6.

Firstly computer-based Pre-Test was conducted to determine the learner's knowledge level in the object-oriented programming domain. Each test had a total of 8 questions. The questions target the students' concepts of object-oriented programming. We designed Pre-Test and Post-Test and then got it approved by an object-oriented programming instructor. The questions were graded with digit 1 point for each correct answer and digit 0 for the wrong answer.

Secondly, Students were tutored regarding the use of the system and functionality. The learners were explained regarding the user interface, functionalities and especially collaborative perspective of the system that how they can best collaborate with their peers. Students were encouraged to follow the collaborative structure of collaborative learning with their peers. Participants were encouraged to discuss/negotiate with peers to construct a new level of knowledge. Also learning participants were briefed on how they can best collaborate and every member of the group must be given equal opportunity to contribute his/her concepts. After knowledge sharing and helping peers, the learners were directed to an understanding level and a group solution.

Thirdly, intervention session, where students first experienced ITSCL individually and then collaboratively. During Individual learning, single student intervenes ITSCL. This intervention was provided for learner-ITS interaction. ITSCL taught eight related concepts of pre and Post-Tests. ITSCL posted questions to each learner, and the learner answered the questions individually. ITSCL provided adaptive feedback and hints to improve the knowledge level of the students. During Collaborative learning procedures, students $\log$ in to the collaborative view of learning and join the peer learners for collaborative learning. The total number of students was divided into seven groups; each collaborative group was consisting of four students. Students were observed to be active, engaged and interested in the collaborative learning environment of ITSCL.

Fourthly, Students attempted Post-Test individually for both individual and collaboratively told conditions for statistical analysis of Paired T-Tests.

Finally, learners fill the post-experiment survey to share their experience about ITSCL usability, performance, collaborative nature and future prospective of the system.

Overall, experiment procedures are presented in Fig. 6.

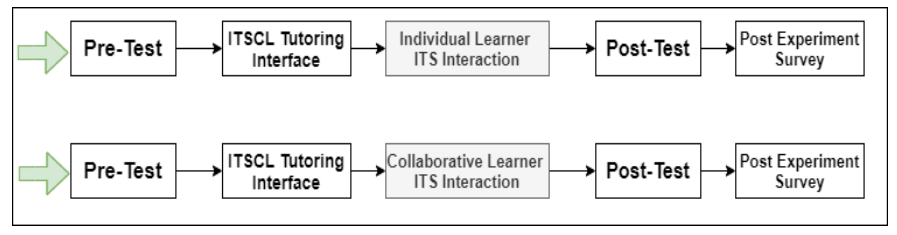

Fig. 6. Study Procedure.

\section{E. Measures}

Basically, two measures were taken for the evaluation of the ITSCL. Firstly, students learning gains were taken from pre and Post-Test in individual and collaborative conditions. Secondly, students' perceptions about the ITSCL were recorded through the post-experiment survey.

1) Measurement of learning gain: Pre-Test and Post-Test were taken individually to access learner's conceptual knowledge of object-oriented programming domain in individual and collaborative conditions. These questions were interrelated and counter checked for balance. The test was administered on the computer. There were total 8 questions in each test. For each correct answer, learners received 1 mark. For one incorrect answer learners were marked as 0. Points obtained from all questions are added. Learning gain is determined with the following expression.

Learning gain $=$ Post_Test score - Pre_Test score

We further performed descriptive statistics of frequency analysis. Frequency analysis is the number of occurrence of scores obtained by the students that is, 5 students get 2 marks, and then its frequency is 5. Frequency analysis showed overall students' performance on Pre-Test and Post-Test in both individual and collaborative conditions.

2) Post experiment survey: After sessions with participants, research conducted a post-experiment survey to record the participant's response and experience about ITSCL. Post experiment survey consisted of five questions regarding ITSCL performance, efficiency, usability, and application. These five questions tend to find the different perceptions of using ITSCL about usability, knowledge gain, student satisfaction, a collaborative learning environment, and its application.

Total of 28 participants answered these questions and their responses are measured on the scale from 1 to 5 .

\section{F. Analysis}

To analyze the learning gains from Pre-Test and Post-Test, the study performed statistical analysis of Paired T-Tests. To trace student learning gain, a Paired T-Test was applied on the Pre-Test and Post-Test scores in both individual and collaborative conditions. Paired T-Test analysis measure the dependency between dependent variables. The Paired T-Test is a parametric approach that compares the means of the same population applying two different procedures. Paired T-Test gives t-value, which shows the significant difference between Pre-Test and Post-Test. Paired T-Test works on two hypothesizes, null and alternative hypothesis.

Null Hypothesis:

$\mathrm{H}_{0}$ : Pre-Test and Post-Test have no difference

Alternative Hypothesis:

$\mathrm{H}_{1}$ : Pre-Test and Post-Test difference matter 


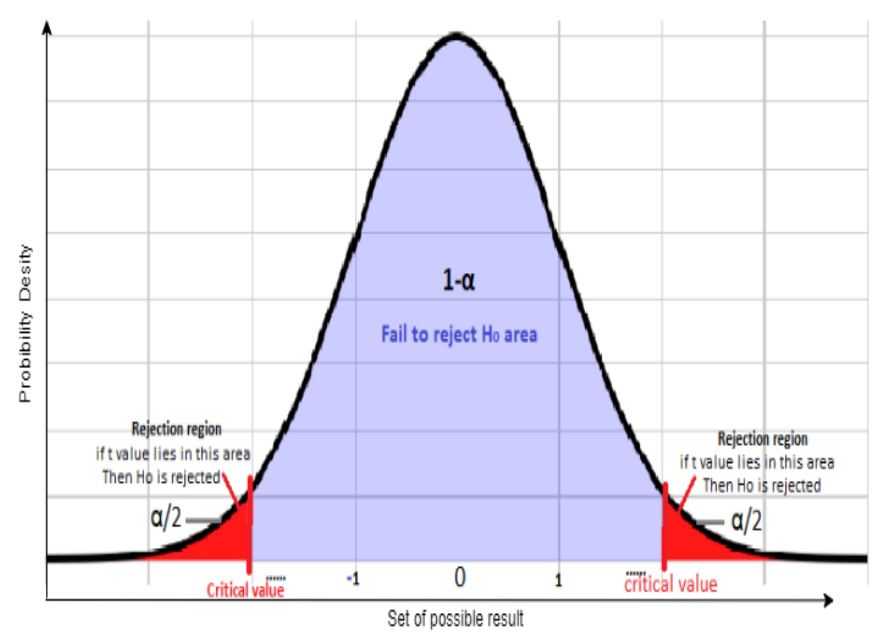

Fig. 7. P Valued Graph.

Performing Paired T-Test on individual and collaborative conditions if $T$ value lies in the rejection region then the null hypothesis is rejected otherwise null hypothesis fails to reject and the alternative hypothesis is accepted. This result is presented on a two-tailed p-value in Fig. 7.

The critical value is the area that is a critical point between rejected areas and failed to reject area and can be found out from $\mathrm{t}$-table using the degree of freedom.

Degree of freedom $=\mathrm{df}=\mathrm{n}-1$

Keeping $95 \%$ confidence level is inferential statistics that means there is $95 \%$ chance that the null hypothesis will be rejected if $\mathrm{T}$ values lie in the rejected region. So $95 \%$ confidence level means:

$\alpha=0.95$

The above p-value graph shows the significant difference, that how much improvement is observed and is analyzed from the mean value, standard deviation, t-value, and significance. Results of Paired T-Tests are also evaluated on the mean value, standard deviation, t-value, and significance show learning gain improvement.

We also performed descriptive statistics of frequency analysis. Frequency analysis showed overall students' performance on the Pre-Test and Post-Test scores. This analysis shows that some weak students got zero, or could score one or two marks in the Pre-Test, improved their marks in the Post-Test. So we trace the frequency table of marks obtained in Pre-Test and Post-Test scores in individual and collaborative conditions to trace the effectiveness and performance of ITSCL.

Subsequently, we also analyzed student perception of using ITSCL. A Post-experiment survey was performed using a Likert scale. A total of 28 students participated in the survey. We calculated the mean and percentages of students' performance.

\section{VIII.RESULTS AND DISCUSSION}

The results of Paired T-Test and frequency analysis show improvement in learning gain and performance. The result of the post-experiment shows the student's perception of using ITSCL. These are given below.

\section{A. Learning Gain}

Learning gain was measured from Paired T-Test and frequency analysis. Results from both these evaluations are given below:

1) Paired T-Test Result: A Paired T-Test was applied on Pre-Test and Post-Test in individual and collaborative conditions.

$\mathrm{T}$ value of Paired T-Test was -4.121 that lie in the rejection region as shown in Fig. 8. However, the null hypothesis is rejected and it concludes that it is significantly different in Pre-Test and Post-Test in the individual condition. Therefore, it concluded to fail the $\mathrm{H}_{\mathrm{o}}$ hypothesis.

Further interpretation of Paired T-Test gives mean, standard deviation, t-value, and significant difference. For individual condition, Paired T-Test was applied on Pre-Test and Post-Test. Keeping 27 degrees of freedom, the mean of Post-Test (4.46) was higher than the pre-test (3.04). Moreover, there was a significant difference of $p(0.0001)$ that is less than 0.05 between Pre-Test and Post-Test. These results show a significant difference between Pre-Test and Post-Test. Learning gain was measured by taking the difference between Post-Test and Pre-Test, then t-test was applied to calculate mean (1.892), standard deviation (1.448) and highly significant $\mathrm{p}$ value $(\mathrm{p}<0.05)$.

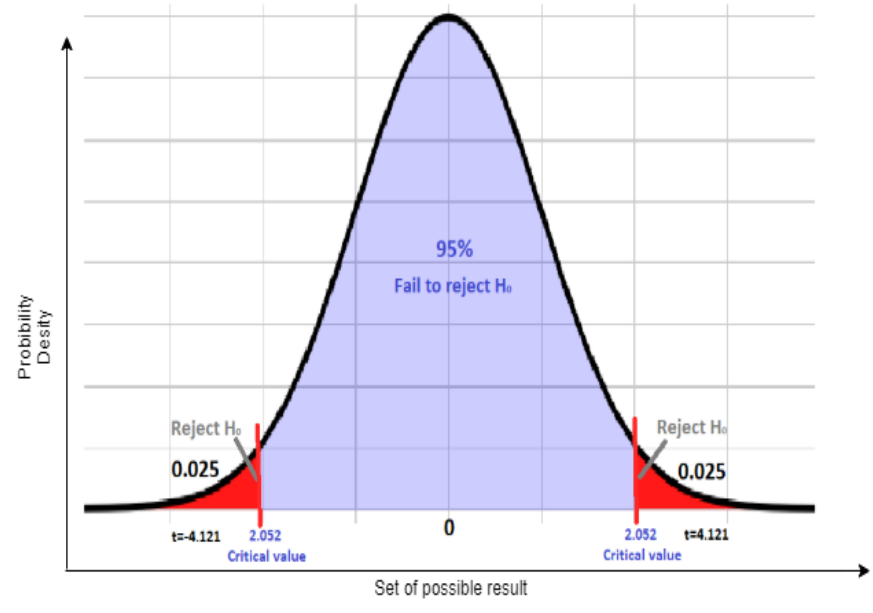

Fig. 8. P-Value Paired Test Graph for Individual Condition.

In collaborative conditions, $\mathrm{T}$ value of Paired T-Test was 5.872 that lie in the rejection region as shown in Fig. 9, thus null hypothesis is rejected and concluded that there is a significant difference in Pre-Test and Post-Test in the individual condition. Therefore, it concluded to fail the $\mathrm{H}_{\mathrm{o}}$ hypothesis. 


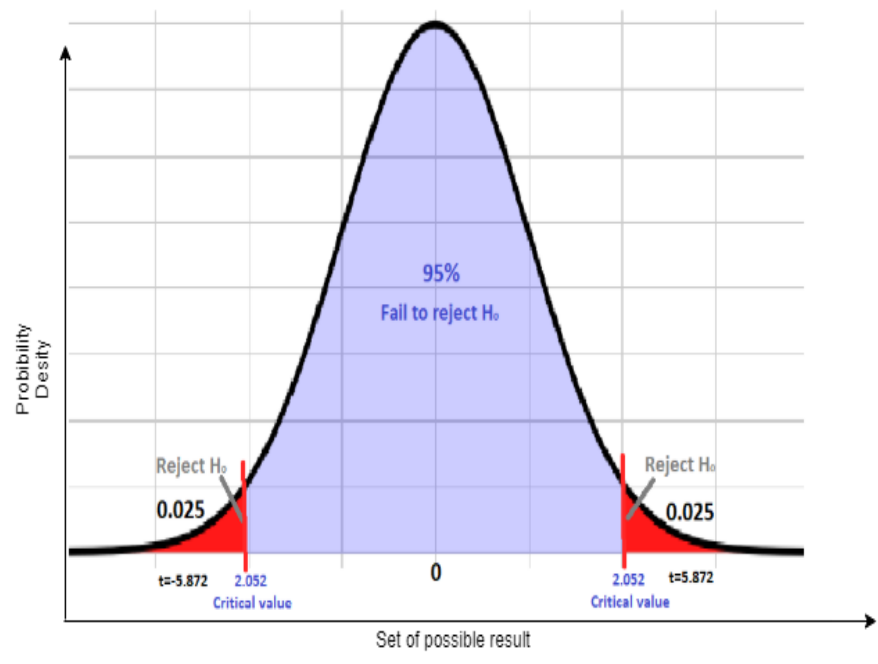

Fig. 9. P-Value Paired Test Graph for Collaborative Condition.

To measure the improvement level is analyzed from the mean value, standard deviation, t-value, and significance value. Keeping 27 degrees of freedom, the mean of Post-Test (6.035) was higher than the Pre-Test (4.035). Also, there was a significant difference of $p(0.0001)$ that is less than 0.05 between Pre-Test and Post-Test. These results show a high significant difference between Pre-Test and post-test. Learning gain was measured by making a difference between Post-Test and Pre-Test, then t-test was applied to calculate mean (2.571), standard deviation (1.77) and highly significant $(\mathrm{p}<0.05)$. The overall Paired T-Test result is given in Table I.

TABLE I. PAIRED T-TEST RESULTS

\begin{tabular}{|l|l|l|l|l|l|l|l|l|}
\hline \multirow{2}{*}{ Conditions } & & \multicolumn{3}{|l|}{ Pre Test } & \multicolumn{2}{l|}{ Post Test } & \multicolumn{2}{l|}{ Gain } \\
\cline { 3 - 8 } & \multirow{2}{*}{$\mathbf{N}$} & \multicolumn{2}{|l|}{ Paired T-Test Result } \\
\cline { 3 - 8 } & & $\begin{array}{l}\text { Mean } \\
(\mu)\end{array}$ & $\begin{array}{l}\text { SD } \\
(\sigma)\end{array}$ & $\begin{array}{l}\text { Mean } \\
(\mu)\end{array}$ & $\begin{array}{l}\text { SD } \\
(\sigma)\end{array}$ & $\begin{array}{l}\text { Mean } \\
(\mu)\end{array}$ & $\begin{array}{l}\text { SD } \\
(\sigma)\end{array}$ \\
\hline Individual & 28 & 3.04 & 1.972 & 4.46 & 1.478 & 1.892 & 1.448 \\
\hline Collaborative & 28 & 4.035 & 1.764 & 6.035 & 1.580 & 2.571 & 1.77 \\
\hline
\end{tabular}

\section{B. Individual Learning Frequency Measurement}

The study calculated the frequency analysis of Pre-Test and Post-Test. Frequency analysis simply counts the number of times that each variable occurs. Here Frequency analysis shows the frequency or number of students in Pre-Test and Post-Test. Applying descriptive statistical analysis showed an interesting measure of student performance. The study observed that in the Pre-Test there are students who performed weak or average, improved their performance in the Post-Test.

Considering Pre-Test scores some students got 1 or 2 marks, while in Post-Test frequency analysis there were no students with results of 1 or 2 marks. This frequency analysis showed improvement students learning gain in individual learning. The frequency analysis table of Pre-Test and PostTest is given in Fig. 10.

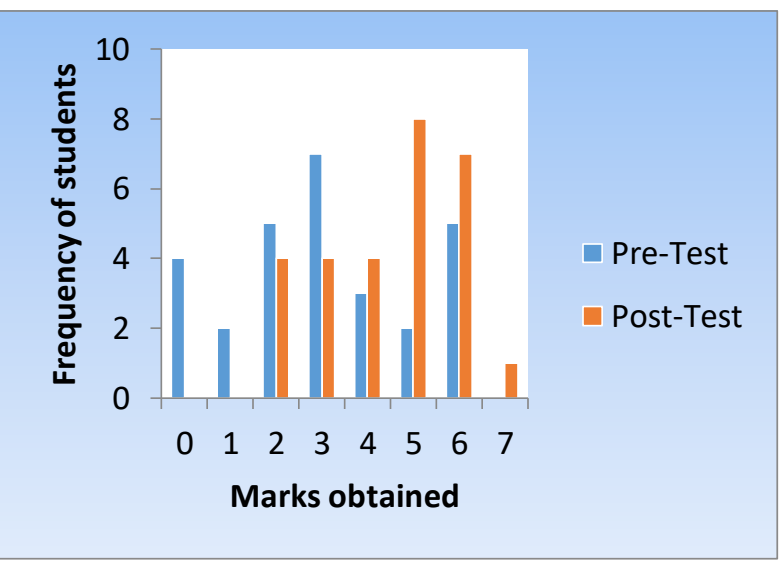

Fig. 10. Pre-Test and Post-Test Frequency Comparison.

\section{Collaborative Learning Frequency Measurement}

The study evaluates the frequency analysis for collaborative learning as well. Because in collaborative learning there is a small group of learners involved in the learning environment, so it might have a different result. Applying frequency analysis there were interesting results that illustrates improvement in the performance. In Pre-Test frequency analysis some students got 1 or 2 marks, but in the Post-Test, there were no students in 1 or 2 marks. Likewise, only two students in the Pre-Test got only full eight marks, But in the Post-Test, seven students obtained full marks. Overall frequency analysis of Pre-Test and Post-Test is presented in Fig. 11.

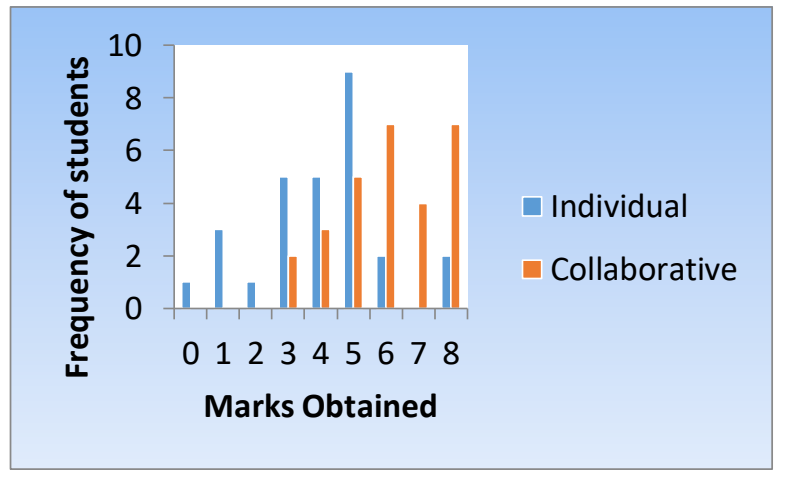

Fig. 11. Frequency Graph in Collaborative Condition.

\section{Comparing Individual and Collaborative Learning Gain}

Analyzing statistical measurements, we found interesting facts that a collaborative learning environment resulted in high learning gain as compared to individual learning conditions. This conclusion was drawn from calculating the mean value of both learning gain shown in Table II, where collaborative learning condition has a high mean than individual condition.

TABLE II. COMPARING LEARNING GAINS

\begin{tabular}{|l|l|l|}
\hline \multirow{3}{*}{ Conditions } & \multicolumn{2}{|l|}{ Learning Gain } \\
\cline { 2 - 3 } & T-Test Result & \multicolumn{2}{|c|}{ SD $(\sigma)$} \\
\cline { 2 - 3 } & Mean $(\mu)$ & 1.449 \\
\hline Individual & 1.89 & 1.772 \\
\hline Collaborative & 2.571 & \\
\hline
\end{tabular}




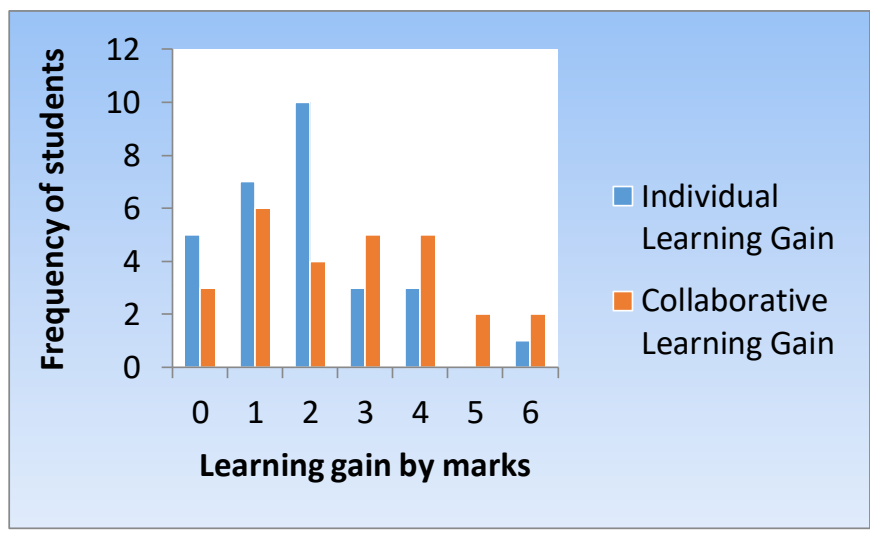

Fig. 12. Individual and Collaborative Learning Gain.

For additional interpretation of comparing individual and collaborative learning gains, bar charts are plotted in Fig. 12. These representations also clearly show that collaborative learning has better results than individual learning.

\section{E. Post Experiment Survey}

Table III shows the participants' responses and experience of using ITSCL. Students' responses were recorded for about five different questions. These questions were related to usability, performance, collaborative learning, and future application perspective.

1) ITSCL usability feature: ITSCL provides interactive environment and user interface. User interface in an important aspect of human computer interaction and computer supported collaborative learning. User interface prospective is to facilitate learners to have interactive user interface. The post experiment survey showed significant interest of learners that ITSCL provide interactive environment. Post experiment survey indicated that about $90 \%$ as shown in Table IV, learners agreed that user interface was user friendly and facilitated learners to understand system. Graphical representation of experimental results of question 1 is presented in pie char in Fig. 13.

2) ITSCL helps in learning gain: ITSCL provides full control of tutoring and facilitates user in learning process. This is most the significant aspect to evaluate ITSCL. This evaluation helps to find weather ITSCL help learners to tutored and improve their learning gains. The Post experimentation resulted in participants $39 \%$ strongly agreed and $51 \%$ agreed that ITSCL helped them in tutoring and facilitate in learning process. Overall students' responses to questions 2 are shown in Table V. Fig. 14 below illustrate the results of users' satisfaction using pie chart.

3) User satisfaction: ITSCL is more interactive and enhances user satisfaction due to collaborative nature. ITSCL extend one-to-one ITS for collaboration script. In collaborative view of learning, learners collaborate each other's in learning process. If the system is more interactive due to collaborative nature, this will be helpful in improving learning gain of collaborative students. Post experiment evaluation, showed learners satisfaction that ITSCL facilitate learners in constructive collaborative knowledge. Post experiment showed 32\% strongly agreed and $48 \%$ user satisfaction in supportive collaborative nature. Students' responses to questions 3 are presented in Table VI. User satisfaction due to collaborative nature is graphically presented in Fig. 15.

4) ITSCL collaborative methodology: ITSCL methodology is more useful for sharing knowledge with other peers. ITSCL proposed a novel framework model for integrating CSCL and ITS. It is important to evaluate ITSCL for knowledge sharing aspect of collaborative learners. This evaluation shows $57 \%$ strongly agree and $32 \%$ agree choice of the participants. Table VII displays the usefulness of ITSCL proposed framework for sharing knowledge among the learners and graphically depicts the results in Fig. 16.

TABLE III. POST EXPERIMENT STUDENTS RESPONSES

\begin{tabular}{|l|l|l|l|l|l|l|}
\hline & \multicolumn{5}{|c|}{$\begin{array}{l}\text { <strongly agree...strongly } \\
\text { disagree> }\end{array}$} & \multirow{2}{*}{ Mean } \\
\cline { 2 - 7 } & $(5)$ & $(4)$ & $(3)$ & $(2)$ & $(1)$ & \\
\hline $\begin{array}{l}\text { ITSCL provides an interactive } \\
\text { environment and user interface. }\end{array}$ & 08 & 17 & 0 & 2 & & 4.035 \\
\hline $\begin{array}{l}\text { ITSCL provides full control of } \\
\text { tutoring and facilitates the user } \\
\text { in the learning process. }\end{array}$ & 11 & 15 & 1 & 1 & 0 & 4.178 \\
\hline $\begin{array}{l}\text { ITSCL is more interactive and } \\
\text { enhances user's satisfaction due } \\
\text { to collaborative nature. }\end{array}$ & 10 & 15 & 0 & 3 & 0 & 4.14 \\
\hline $\begin{array}{l}\text { ITSCL methodology is more } \\
\text { useful for sharing knowledge } \\
\text { with other pairs. }\end{array}$ & 16 & 9 & 0 & 2 & 1 & 4.321 \\
\hline $\begin{array}{l}\text { ITSCL methodology can be } \\
\text { used as an effective technique } \\
\text { for teaching classes in the } \\
\text { future. }\end{array}$ & 10 & 14 & 1 & 2 & 1 & 4.071 \\
\hline
\end{tabular}

TABLE IV. QUESTION 1RESPONSES

\begin{tabular}{|l|l|l|l|l|l|}
\hline $\begin{array}{l}\text { Total } \\
\text { Participants }\end{array}$ & $\begin{array}{l}\text { Strongly } \\
\text { Agree }\end{array}$ & Agree & Uncertain & Disagree & $\begin{array}{l}\text { Strongly } \\
\text { Disagree }\end{array}$ \\
\hline 28 & 08 & 17 & 0 & 2 & 1 \\
\hline
\end{tabular}

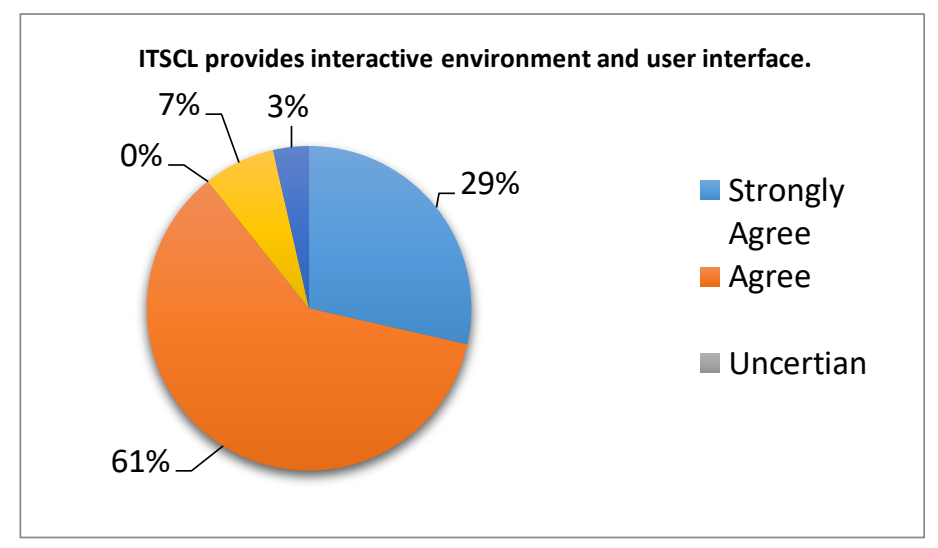

Fig. 13. Overall Results of Question 1. 
TABLE V. QUESTION 2 RESPONSES

\begin{tabular}{|l|l|l|l|l|l|}
\hline $\begin{array}{c}\text { Total } \\
\text { Participants }\end{array}$ & $\begin{array}{l}\text { Strongly } \\
\text { Agree }\end{array}$ & Agree & Uncertain & Disagree & $\begin{array}{l}\text { Strongly } \\
\text { Disagree }\end{array}$ \\
\hline 28 & 11 & 15 & 1 & 1 & 0 \\
\hline
\end{tabular}

ITSCL is more interactive and enhance user satisfaction due to collaborative nature.

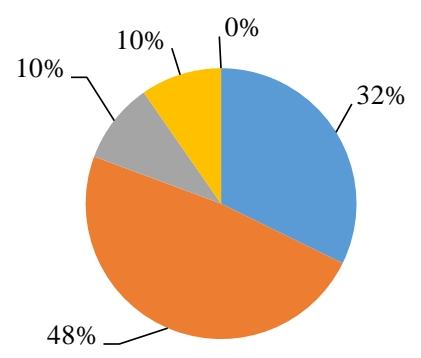

$$
\begin{aligned}
& \text { Strongly Agree } \\
& \text { Agree } \\
& \square \text { Uncertain } \\
& \square \text { Disagree } \\
& \text { - Strongly Disagree }
\end{aligned}
$$

Fig. 14. Overall Results of Question 2.

TABLE VI. QUESTION 3 RESPONSES

\begin{tabular}{|l|l|l|l|l|l|}
\hline $\begin{array}{l}\text { Total } \\
\text { Participants }\end{array}$ & $\begin{array}{l}\text { Strongly } \\
\text { Agree }\end{array}$ & Agree & Uncertain & Disagree & $\begin{array}{l}\text { Strongly } \\
\text { Disagree }\end{array}$ \\
\hline 28 & 10 & 15 & 0 & 3 & 0 \\
\hline
\end{tabular}

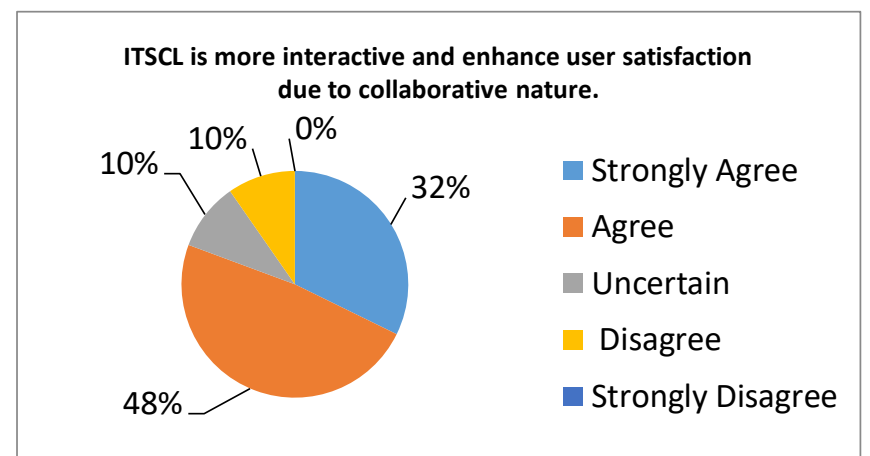

Fig. 15. Overall Results of Question 3.

TABLE VII. QUESTION 4 RESPONSES

\begin{tabular}{|l|l|l|l|l|l|}
\hline $\begin{array}{l}\text { Total } \\
\text { Participants }\end{array}$ & $\begin{array}{l}\text { Strongly } \\
\text { Agree }\end{array}$ & Agree & Uncertain & Disagree & $\begin{array}{l}\text { Strongly } \\
\text { Disagree }\end{array}$ \\
\hline 28 & 16 & 9 & 0 & 2 & 1 \\
\hline
\end{tabular}

ITSCL methodology is more useful for sharing knowledge with other pairs

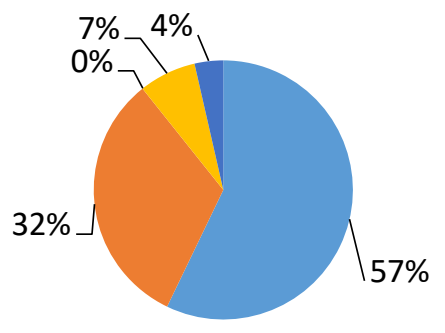

- Strongly Agree

n Agree

Uncertain

$\square$ Disagree

- Strongly Disagree

Fig. 16. Overall Results of Question 4.

5) ITSCL Future Implication: ITSCL methodology can be used as an effective technique for teaching classes in future. ITS have been used practically successfully in classroom for teaching. Single learner ITS provide cognitive support for individual learning. However in classroom teaching is almost in collaborative nature. As ITSCL provide support for learners in individual and collaborative learning environment, so it is important to evaluate ITSCL suitability for effectiveness in classroom teaching. Interestingly participants 36\% strongly agreed and 50\% agreed, ITSCL could be applicable as an effective technique for classroom teaching. Participants' responses to question 5 are shown in Table VIII and illustrated in Fig. 17.

TABLE VIII. QUESTION 5 RESPONSES

\begin{tabular}{|l|l|l|l|l|l|}
\hline $\begin{array}{l}\text { Total } \\
\text { Participants }\end{array}$ & $\begin{array}{l}\text { Strongly } \\
\text { Agree }\end{array}$ & Agree & Uncertain & Disagree & $\begin{array}{l}\text { Strongly } \\
\text { Disagree }\end{array}$ \\
\hline 28 & 10 & 14 & 1 & 2 & 1 \\
\hline
\end{tabular}

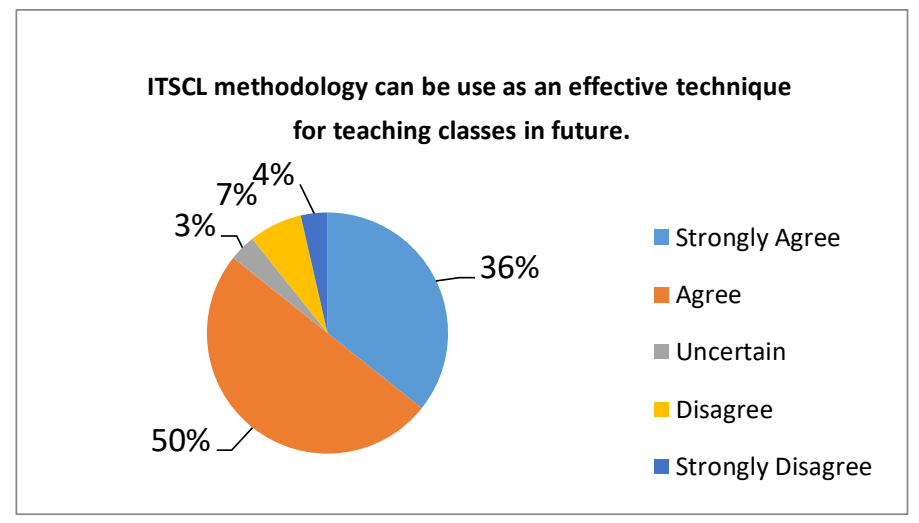

Fig. 17. Overall Results of Question 5.

\section{CONCLUSION AND Future WORK}

The research work was related to the redesigning of a traditional one-to-one tutoring system to facilitate collaborative learning. In this research study, we integrated ITS and CSCL to propose a design framework of Intelligent Tutoring Supported Collaborative Learning (ITSCL) that supports both individual and collaborative learning. Individual learning is achieved by leaner-ITSCL interaction. While collaborative learning is achieved by groups of learnersITSCL interaction and learner-learner interaction. This extension of ITS for collaborative learning could be more effective because it allows students to share knowledge, articulate reasoning and misconceptions and reflect upon their knowledge with peer learners, thus developing a deeper understanding. Learners sharing knowledge, misconception, and reasoning, reflect upon their earlier responses and had an opportunity to build fluency with individual capability. The strengths of individual and collaborative learning are integrated into ITSCL to enhance the students learning. This study also developed a prototype of a proposed model of ITSCL for evaluation. ITSCL provides functionalities to both individual learner and groups of learners. After the implementation, we evaluated ITSCL through experiments. ITSCL evaluated for both individual and collaborative 
learning. A group of 28 students participated in experiments and learning gains of students and the post-experiment survey was recorded. Learning gains were measured from Paired TTest and frequency analysis showed significant learning gains and improvement in the learning process. Another evaluation of the post-experiment survey was collected to evaluate the efficiency and performance of ITSCL. This study achieved its goal to have both collaborative and cognitive support with improved learning performance.

This research indicates a promising direction to explore the support of collaborative learning that affects learning and social participation. In this study, ITSCL is not analyzing intra-group communication and learner interactions, therefore, further research is needed to explore this gap and ITSCL should provide real-time feedback on collaborative activities. Another future research perspective is group cognition by an intelligent tutoring system and predicting student performance in a collaborative learning paradigm. Further research is needed on group cognition of collaborative learners by intelligent tutoring systems. Our study indicates that this would be a promising direction for future research to explore.

\section{REFERENCES}

[1] Hartley, JR, and Sleeman, DH, "Towards more intelligent tutoring system", International Journal of machine studies, Volume 5, Issue 2, pp. 215-236, April 1973.

[2] Rachel Carlos, Seiji Isotania, Carla Rodriguezac, Kamila Lyra, Patrícia Jaques, Ig Bittencour, "Affective states in computer-supported collaborative learning: Studying the past to drive the future", Computer and Education 120, Volume 120, pp.29-50, 2018.

[3] Yiping Lou, Philip C. Abrami and Sylvia d'Apollonia, "Small group and individual learning with technology: A meta-analysis", Review of Educational Research, Vol. 71, No. 3, pp.449-521, 2001.

[4] I. Magnisalis, S. Demetriadis and A. Karakostas, "Adaptive and Intelligent Systems for Collaborative Learning Support: A Review of the Field," in IEEE Transactions on Learning Technologies, Vol. 4, no. 1, pp. 5-20, Jan.-March 2011.

[5] Jun Xie, Shirin Mojarad, Keith Shubeck, Alfred Essa, Ryan S. Baker and Xiangen $\mathrm{Hu}$, "Student Learning Strategies and Behaviors to Predict Success in an Online Adaptive Mathematics Tutoring System", 10th International Conference on Educational Data Mining, January 2017.

[6] Salgueiro, Fernando Costa, Guido Cataldi, Zulma Lage, Fernando García Martínez, Ramón, "Redefinition of basic modules of an intelligent tutoring system: the tutor module." VII Workshop de Investigadores en Ciencias de la Computación, pp. 444-448, 2005.

[7] A. C. Graesser, P. Chipman, B. C. Haynes and A. Olney, "AutoTutor: an intelligent tutoring system with mixed-initiative dialogue," in IEEE Transactions on Education, vol. 48, no. 4, pp. 612-618, Nov. 2005.

[8] Tchounikine, Pierre \& Rummel, Nikol \& Mclaren, Bruce, "Computer Supported Collaborative Learning and Intelligent Tutoring Systems", Advances in Intelligent Tutoring Systems, SCI 308, pp. 447-463, 2010.

[9] M. Virvou, C. Troussas and S. Sidiropoulos, "Collaborative Support in a Multilingual Tutoring System," 2012 Eighth International Conference on Intelligent Information Hiding and Multimedia Signal Processing, Piraeus, pp. 502-505, 2012.

[10] M. Virvou, E. Alepis and C. Troussas, "User Modeling on Communication Characteristics Using Machine Learning in ComputerSupported Collaborative Multiple Language Learning," 2012 IEEE 24th International Conference on Tools with Artificial Intelligence, Athens, pp. 1088-1093, 2012.

[11] Epstein, Daniel \& Pinho, Isis \& Acosta, Otavio \& Reategui, Eliseo. (2013). "Inquiry-based learning environment using intelligent tutoring system", Proceedings - Frontiers in Education Conference, 1072-1074. 10.1109/FIE.2013.6684991, 2013.
[12] Ronald Cole, Cindy Martin, Timothy Weston, Liam Devine, Jeannine Myatt, Brandon Helding, Sameer Pradhan, Margaret McKeown, Samantha Messier, Jennifer Borum, and Wayne Ward, "One-on-one and Small Group Conversations with an Intelligent Virtual Science Tutor", Computer Speech \& Language, Volume 50, pp. 157-174, July 2018.

[13] Chopade, P., Khan, S., Stoeffler, K., Edwards, D.T., Rosen, Y., \& Davier, A.V, "Framework for Effective Teamwork Assessment in Collaborative Learning and Problem Solving", International Journal of Artificial Intelligence in Education, pp. 1-40, 2017.

[14] Sottilare, R.A., Baker, R.S., Graesser, A.C. et al. Special Issue on the Generalized Intelligent Framework for Tutoring (GIFT): Creating a Stable and Flexible Platform for Innovations in AIED Research. Int J Artif Intell Educ 28,139-151, 2018.

[15] Kaitlyn Ouverson, Mariangely Iglesias-Pena, Jamiahus Walton, Stephen B Gilbert,and Michael C Dorneich, "What Intelligent Team Tutoring Systems Can Learn from Human-Agent Teams", proceeding of Techmind Society, USAArticle No. 28, pp. 1, 2018.

[16] Jennifer K. Olsen, Daniel M. Belenky, Vincent Aleven, Nikol Rummel, "Intelligent Tutoring Systems for Collaborative Learning: Enhancements to Authoring Tools", International Conference on Artificial Intelligence in Education, AIED: Artificial Intelligence in Education, pp. 900-903, 2013.

[17] Daniel Belenky1, Michael Ringenberg1, Jennifer Olsen1, et al, "Using Dual Eye-Tracking Measures to Differentiate Between Collaboration on Procedural and Conceptual Learning Activities", 10th International Conference on Computer Supported Collaborative Learning Madison, Wisconsin, pp. 15-19, June 2013.

[18] Jennifer K. Olsen et al, "Using an Intelligent Tutoring System to Support Collaborative as well as Individual Learning", ITS, 2014, LNCS 8474, pp. 134-143, 2014.

[19] Jennifer K. Olsen, Vincent Aleven, and Nikol Rummel, "Toward Combining Individual and Collaborative Learning Within an Intelligent Tutoring System", AIED, Springer International Publishing Switzerland, LNAI 9112, pp. 848-851, June 2015.

[20] Jennifer K. Olsen, Vincent Aleven, and Nikol Rummel, "Adapting Collaboration Dialogue in Response to Intelligent Tutoring System Feedback", Artificial Intelligence In Education AIED, 2015, LNAI 9112, pp. 748-75, 2015.

[21] Jennifer K. Olsen, Vincent Aleven, and Nikol Rummel, "Learning Alone or Together? A Combination Can Be Best!", CSCL Proceedings, 2017.

[22] Olsen, J., Sharma, K., Aleven, V., \& Rummel, N., "Combining Gaze, Dialogue, and Action from a Collaborative Intelligent Tutoring System to Inform Student Learning Processes", In Kay, J. and Luckin, R. (Eds.) Rethinking Learning in the Digital Age: Making the Learning Sciences Count, 13th International Conference of the Learning Sciences (ICLS), V.No. 2, 2018.

[23] Jennifer K. Olsen, Nikol Rummel and Vincent Aleven, "It is not either or: An initial investigation into combining collaborative and individual learning using an ITS", International Society of the Learning Sciences, Inc.14, pp. 353-381, 2019.

[24] Rachel Harsley, Nick Green, Barbara Di Di Eugenio, Satabdi Aditya, Davide Fossati and Omar Al Zoubi, "Collab-ChiQat: A Collaborative Remaking of a Computer Science Intelligent Tutoring System”, CSCW '16 Companion: Proceedings of the 19th ACM Conference on Computer Supported Cooperative Work and Social Computing Companion, pp.281-284, February 2016.

[25] Harsley R., Di Eugenio B., Green N., Fossati D., Acharya S. "Integrating Support for Collaboration in a Computer Science Intelligent Tutoring System”. In: Micarelli A., Stamper J., Panourgia K. (eds) Intelligent Tutoring Systems. ITS 2016. Lecture Notes in Computer Science, vol. 9684, pp. 227-233, 2016.

[26] Rachel Harsley et al, "Interactions of Individual and Pair Programmers with an Intelligent Tutoring System for Computer Science”, SIGCSE '17 Proceedings of the ACM SIGCSE Technical Symposium on Computer Science Education, Washington USA. PP. 285-290, March 2017.

[27] Rachel Harsley et al "Enhancing an Intelligent Tutoring System to Support Student Collaboration: Effects on Learning and Behavior", AIED, LNAI 10331, pp. 519-522, June 2017. 
[28] Roger Nkambou, Jacqueline Bourdeau, and Riichiro Mizoguchi, "Introduction: What Are Intelligent Tutoring Systems, and Why This Book?", Advances in Intelligent Tutoring Systems, SCI 308, pp. 1-12, 2010.

[29] Daniel D. Suthers, "Architectures for Computer-Supported Collaborative Learning", ICALT '01: Proceedings of the IEEE International Conference on Advanced Learning Technologies , August 2001.

[30] Levette Dames et al, "Active Student Engagement through the Use of WebEx, MindTap, and a Residency Component to Teach a Masters
Online Group Counseling Course", Handbook of Research on Transformative Digital Content and Learning Technologies, Chapter: 14, Publisher: IGI Global, Editors: Jared Keengwe, Prince Hycy Bull, pp.245-268, 2016.

[31] Raja M. Suleman et al, "NDLtutor: An Automated Conversational Agent to Facilitate Metacognitive Skills in Fully-Negotiated OLMs", International Conference on Intelligent Tutoring Systems ITS, pp. 354360, 2016.

[32] Ioannis Magnisalis et al, "Can peers rate reliably as experts in small CSCL groups?", 13th International Conference on Intelligent Tutoring Systems, ITS, 2016. 